\title{
Resveratrol inhibits the IL-1 $\beta$-induced expression of MMP-13 and IL-6 in human articular chondrocytes via TLR4/MyD88-dependent and -independent signaling cascades
}

\author{
HAILUN GU ${ }^{1}$, YONGLIANG JIAO ${ }^{2,3}$, XIAOLU YU ${ }^{2}$, XINGYAO LI $^{2}$, WEI WANG ${ }^{1}$, LIFENG DING ${ }^{1}$ and LI LIU ${ }^{2}$ \\ ${ }^{1}$ Department of Orthopedics, Shengjing Hospital, China Medical University, Shenyang, Liaoning 110004; \\ ${ }^{2}$ Department of Nutrition and Food Hygiene, School of Public Health, China Medical University, Shenyang, Liaoning 110122; \\ ${ }^{3}$ Department of Humanities and Social Science, Jilin Institute of Physical Education, Changchun, Jilin 130022, P.R. China
}

Received January 15, 2016; Accepted February 3, 2017

DOI: $10.3892 /$ ijmm.2017.2885

\begin{abstract}
The natural polyphenolic compound, resveratrol, has been shown to exhibit anti-osteoarthritic activity. Therefore it is hypothesized that resveratrol may serve as a nutritional supplement to counteract osteoarthritis (OA). However, the mechanisms responsible for these anti-osteoarthritic effects have not yet been fully elucidated. The aim of this study was to determine whether the biological effects of resveratrol against interleukin (IL)-1 $\beta$-induced inflammation in human articular chondrocytes involved both Toll-like receptor 4 (TLR4)/myeloid differentiation factor 88 (MyD88)-dependent and -independent signaling pathways. Human articular chondrocytes derived from patients with OA were stimulated with IL-1 $\beta$, and then co-treated with resveratrol. Cell viability was subsequently evaluated by MTS assays, and the concentrations of matrix metalloproteinase (MMP)-13 and the pro-inflammatory factor, IL-6, were detected in culture supernatants using ELISA. The mRNA and protein levels of downstream mediators of TLR4/ MyD88-dependent and -independent signaling pathways were also assayed by RT-qPCR and western blot analysis, respectively. Our results revealed that resveratrol prevented the IL-1 $\beta$-induced reduction in cell viability. Furthermore, stimulation of the chondrocytes with IL-1 $\beta$ resulted in a significant upregulation of TLR4 and downstream targets of both TLR4/MyD88-dependent and -independent signaling pathways that are associated with the synthesis of MMP-13 and IL-6. Correspondingly, IL-1 $\beta$ induced catabolic and inflammatory responses were effectively reversed by resveratrol. Taken together, these data suggest that resveratrol exerted protective effects against matrix degradation and inflammation in OA-affected chondrocytes by inhibiting both TLR4/MyD88-dependent and -independent signaling
\end{abstract}

Correspondence to: Dr Hailun Gu, Department of Orthopedics, Shengjing Hospital, China Medical University, 36 Sanhao Street, Heping, Shenyang, Liaoning 110004, P.R. China

E-mail: guhailun_@163.com

Key words: Toll-like receptor 4, resveratrol, chondrocytes, matrix metalloproteinase-13, interleukin-6, myeloid differentiation factor 88 pathways. Thus, resveratrol represents a potential treatment for $\mathrm{OA}$ and warrants further investigation.

\section{Introduction}

Osteoarthritis (OA) is a common chronic disease that is characterized by articular cartilage degeneration and secondary bone hyperplasia (1). Correspondingly, OA is a major cause of joint pain and disability in the aging population. At the onset of OA, articular cartilage is affected. The integrity of joint structures, including subchondral bone, synovium, menisci, ligaments, periarticular muscles and nerves is then affected (2,3). Eventually, the complete loss of articular cartilage can lead to joint deformity and disability (2). Normal articular cartilage is a closed tissue without vascularity, thereby preventing surveillance by the body's immune system. However, in OA, the innate immune system is activated and this plays a role in the induction of inflammatory mediators and specific cellular infiltration (4). The Toll-like receptors (TLRs), a type of pattern recognition receptor, and their signaling pathways are particularly relevant in this process $(5,6)$. TLR4 is the main TLR expressed by chondrocytes (7), and it not only plays important roles in activating immune responses, but is also involved in the pathogenesis of inflammatory diseases. It has been reported that TLR4 is more highly expressed in chondrocytes from patients with OA than in chrondrocytes from OA-free subjects (8). Accordingly, the inhibition of TLR4 has been shown to reduce the upregulation of interleukin (IL)-1 $\beta$ and to interfere with the progression of OA (9). Moreover, in a study on rheumatoid arthritis, the inhibition of TLR4 signaling was shown to attenuate articular damage by blocking the identification of endogenous TLR ligands (10). By contrast, TLR4 activation can also potentially lead to a significant increase in the release of proteoglycan and type II collagen degradation products (11). As previously demonstrated, in human OA-affected chondrocytes, a TLR-dependent catabolic effect is elicited by alarmins (S100A8 and S100A9) (8), thereby suggesting that an anti-anabolic effect is mediated by TLR4 in articular chondrocytes and this may suppress cartilage repair in OA (11). Taken together, these results indicate that the modulation of TLR4-mediated signaling may provide a potential therapeutic option for the treatment of OA. 
Currently, the clinical management of OA is aimed at reducing joint pain and inflammation, since there is no treatment available to successfully restore cartilage (12). Therefore, recent research efforts have focused on the development of novel biological therapies to attenuate and/or reverse cartilage degradation at the molecular level (13). Resveratrol (trans-3,5,4'trihydroxystilbene) is a natural polyphenolic compound that is present in grapes, berries and peanuts (14) and has been shown to exert protective effects against OA by mediating anti-apoptotic, anti-inflammatory and anti-oxidative functions in chondrocytes and animal models $(13,15-19)$. It has also been reported that resveratrol modulates several pathways, including the nuclear factor- $\kappa \mathrm{B}(\mathrm{NF}-\kappa \mathrm{B})(15,20)$, mitogen-activated protein kinase (MAPK) (21), extracellular signal-regulated kinase (ERK), p38 and AKT (22) signaling pathways. Among these, the role of the $\mathrm{NF}-\kappa \mathrm{B}$ signaling pathway is of particular interest. The activation of TLR4 has been shown to induce $\mathrm{NF}-\kappa \mathrm{B}$-dependent apoptosis and the expression of proinflammatory cytokines $(23,24)$. However, the mechanisms through which TLR4/NF- $\kappa \mathrm{B}$ signaling contributes to the pathogenesis of OA are not yet fully understood. The classic TLR4 signaling pathway involves both myeloid differentiation factor 88 (MyD88)-dependent and -independent pathways that mediate signaling via TIR domain-containing adaptor-inducing interferon- $\beta$ (TRIF) (25). Previously, we demonstrated that resveratrol prevents IL-1 $\beta$-induced inflammation in human articular chondrocytes, in part by inhibiting the TLR4/MyD88/NF- $\kappa$ B signaling pathway (26). By contrast, several other studies have reported that resveratrol specifically targets the TRIF complex of the TLR4 signaling pathway in some cell types $(27,28)$.

Therefore, the aim of the present study was to determine whether the biological effects of resveratrol on IL-1 $\beta$-induced human articular chondrocytes involves both TLR4/MyD88-dependent and -independent signaling pathways.

\section{Materials and methods}

Reagents and antibodies. Resveratrol, collagenase type II, and a protease inhibitor cocktail were purchased from Sigma-Aldrich (St. Louis, MO, USA). CellTiter $96{ }^{\circledR}$ Aqueous One Solution reagent was purchased from Promega (Madison, WI, USA). Dulbecco's modified Eagle's medium (DMEM)/Ham's F-12 medium (1:1), and fetal calf serum (FCS) were obtained from HyClone/Thermo Fisher Scientific, Inc. (Logan, UT, USA). IL-1 $\beta$ was purchased from PeproTech (Rocky Hill, NJ, USA). Enzyme-linked immunosorbent assay (ELISA) kits for matrix metalloproteinase (MMP)-13 and IL-6 were obtained from Wuhan Boster Biotechnology, Ltd. (Wuhan, China). RNAiso Plus and a RT-PCR kit were purchased from Takara Biotechnology Co., Ltd. (Dalian, China). A BCA kit was obtained from Beyotime Institute of Biotechnology (Shanghai, China). Polyclonal anti- $\beta$-actin (sc-477787), antiTLR4 (sc-293072), anti-MyD88 (sc-74532), and anti-TNF receptor-associated factor 6 (TRAF6; sc-8409) antibodies were purchased from Santa Cruz Biotechnology, Inc. (Dallas, TX, USA). Antibodies specific for phospho-IL-1 receptor-associated kinase 4 (p-IRAK4) (Thr345/Ser346) (Cat. no. 11927) and anti-TRIF (Cat. no. 4596) were obtained from Cell Signaling Technology,Inc.(Beverly,MA,USA). Anti-mouse and anti-rabbit
Table I. The primer sequences.

\begin{tabular}{|c|c|c|}
\hline Genes & Primer sequences (5'-3') & $\begin{array}{l}\text { Products } \\
\text { (bp) }\end{array}$ \\
\hline$\beta$-actin & $\begin{array}{l}\text { F: CACACTGTGCCCATCTACGA } \\
\text { R: CTCAGTGAGGATCTTCATGAGGTAGT }\end{array}$ & 101 \\
\hline TLR4 & $\begin{array}{l}\text { F: AGGACTGGGTAAGGAATGAGC } \\
\text { R: ATCACCTTTCGGCTTTTATGG }\end{array}$ & 148 \\
\hline MyD88 & $\begin{array}{l}\text { F: CACTCAGCCTCTCTCCAGGT } \\
\text { R: AGTCTTCAGGGCAGGGACA }\end{array}$ & 178 \\
\hline IRAK4 & $\begin{array}{l}\text { F: GCCGCTTCTACAAAGTATGG } \\
\text { R: CCATCACTTTGTAGAAGCGGC }\end{array}$ & 83 \\
\hline TRIF & $\begin{array}{l}\text { F: TCCAAATACCAAGCCGTG } \\
\text { R: TCTGTTCCGATGATGATTCC }\end{array}$ & 149 \\
\hline TRAF6 & $\begin{array}{l}\text { F: CTGGAAGCCCTAAGACAAAGA } \\
\text { R: GGCAAGGAAAGGCACTGTT }\end{array}$ & 191 \\
\hline
\end{tabular}

TLR4, Toll-like receptor 4; MyD88, myeloid differentiation factor 88; IRAK4, IL-1 receptor-associated kinase 4; TRIF, TIR domain-containing adaptor-inducing interferon- $\beta$; TRAF6, TNF-receptor associated factor 6 ; $\mathrm{F}$, forward; $\mathrm{R}$, reverse.

secondary antibodies were purchased from Pierce (Rockford, IL, USA). Enhanced chemiluminescence reagent was obtained from Amersham Biosciences (Buckinghamshire, UK).

Isolation and culture of chondrocytes. This study was approved by the Ethics Committee at the Shengjing Hospital China Medical University (Shenyang, China) and informed consent was obtained from all participants. Chondrocyte isolation and culture were performed as previously described (26). Briefly, knee articular cartilage was obtained from 16 patients with OA (aged 50-70 years) that were undergoing joint replacement surgery. Cartilage slices were digested with $0.25 \%$ trypsin for $1 \mathrm{~h}$ and then with $0.04 \%$ collagenase type II in a $37^{\circ} \mathrm{C}$ water bath overnight. Cells were seeded in $25 \mathrm{~cm}^{2}$ flasks $\left(1-2 \times 10^{5}\right.$ cells $\left./ \mathrm{ml}\right)$ containing DMEM/Ham's F-12 medium supplemented with $10 \%$ FCS, penicillin $(100 \mathrm{U} / \mathrm{ml})$ and streptomycin $(100 \mathrm{U} / \mathrm{ml})$, and the cells were grown at $37^{\circ} \mathrm{C}$ with $5 \% \mathrm{CO}_{2}$. Third passage chondrocytes were used in the experiments.

Identification of cell phenotype. The chondrocytes were seeded on glass coverslips and fixed with $4 \%$ paraformaldehyde for $20 \mathrm{~min}$. The cells were then incubated with $3 \% \mathrm{H}_{2} \mathrm{O}_{2}$ for $10 \mathrm{~min}$ to inhibit endogenous peroxidase activity, and were subsequently blocked with goat serum for $15 \mathrm{~min}$ at room temperature followed by incubation with type II collagen antibody (cat. no. A00517; Wuhan Boster Biotechnology, Ltd.) (1:100) overnight at $4^{\circ} \mathrm{C}$. The following day, the coverslips were washed and incubated with the appropriate biotin-conjugated anti-rabbit secondary antibodies (cat. no. BM2004; Wuhan Boster Biotechnology, Ltd.) for $15 \mathrm{~min}$ at room temperature, then were incubated with streptavidin-biotin complex (SABC, SA1021; Wuhan Boster Biotechnology, Ltd.) for an additional 15 min. The cells were stained with 3,3'-diaminobenzidine (DAB; ZSGB-Bio, Beijing, China) for $10 \mathrm{~min}$ at room 

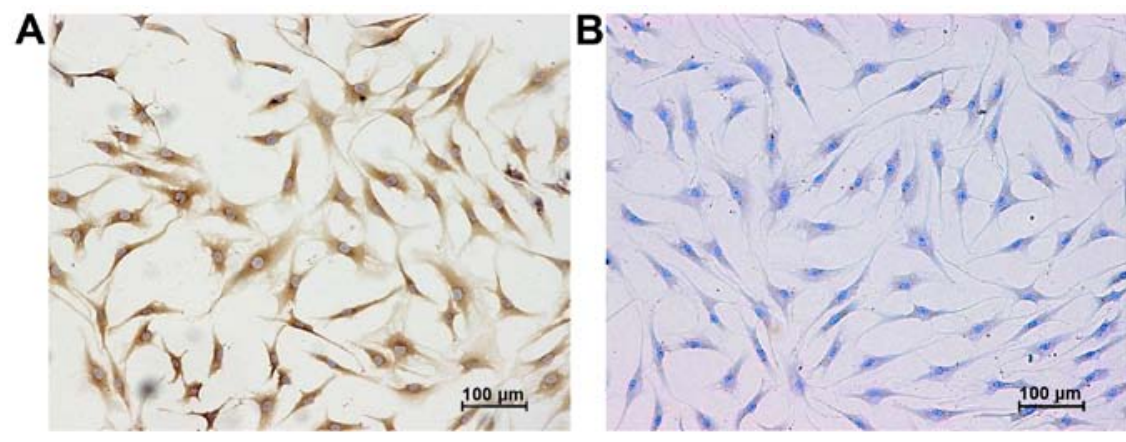

Figure 1. Cultured chondrocytes synthesize type II collagen and proteoglycans. (A) Human articular chondrocytes that were obtained from patients with osteoarthritis (OA), cultured in vitro, and passaged 3 times were fixed in $4 \%$ paraformaldehyde and stained for type II collagen by immunocytochemistry. (B) Toluidine blue staining was also performed to detect proteoglycans. Each slide represents the results obtained from at least 6 donor samples. All images are shown at a magnification of $\mathrm{x} 100$.

temperature followed by hematoxylin (Tianjin Guangfu Fine Chemical Research Institute, Tianjin, China) staining and gradient alcohol dehydration. For the detection of proteoglycans, the cells on coverslips were stained with $1 \%$ toluidine blue (Tianjin Guangfu Fine Chemical Research Institute) for 30 min and were then fixed with $4 \%$ paraformaldehyde.

Cell viability assay. Chondrocytes $\left(5 \times 10^{3}\right.$ cells/well) were seeded in triplicate in 96-well plates and were cultured in the presence or absence of $10 \mathrm{ng} / \mathrm{ml}$ IL- $1 \beta$ and various concentrations of resveratrol $(0,6.25,12.5,25,50,100$, and $200 \mu \mathrm{M})$ for 24,48 , or $72 \mathrm{~h}$ at $37^{\circ} \mathrm{C}, 5 \% \mathrm{CO}_{2}$. Cell viability was determined by MTS assay. Briefly, $20 \mu \mathrm{l}$ of CellTiter $96^{\circledR}$ Aqueous One Solution reagent was pipetted into each well of the 96-well assay plates containing the samples in $100 \mu \mathrm{l}$ of culture medium. The plates were then incubated at $37^{\circ} \mathrm{C}$ in a humidified, $5 \% \mathrm{CO}_{2}$ atmosphere. After $4 \mathrm{~h}$, the absorbance values at $490 \mathrm{~nm}$ were recorded using a microplate reader (Multiskan MK3; Thermo Fisher Scientific, Inc.) and the data were expressed as the means \pm standard deviation (SD) of 3 independent experiments.

Treatment of chondrocytes. Chondrocytes grown in a monolayer were incubated with serum-starved medium ( $0.5 \%$ FCS). After $1 \mathrm{~h}$, the chondrocytes were stimulated with $10 \mathrm{ng} / \mathrm{ml}$ IL-1 $\beta$ for $1 \mathrm{~h}$ before various concentrations of resveratrol $(0$, $6.25,12.5,25,50,100$, and $200 \mu \mathrm{M}$ ) were added to the cells followed by incubation for $24 \mathrm{~h}$.

Reverse transcription-quantitative PCR (RT-qPCR). Total RNA was extracted using RNAiso Plus reagent, according to the manufacturer's instructions. The expression levels of TLR4, MyD88, IRAK4, TRIF and TRAF6 were quantitatively measured using a 7500 real-time PCR detection system (Applied Biosystems, Carlsbad, CA, USA). Each PCR reaction mixture (total volume, $20 \mu \mathrm{l}$ ) included $10 \mu \mathrm{l}$ of $2 \mathrm{X}$ SYBRGreen Master mix (Takara Biotechnology Co., Ltd.), $0.8 \mu \mathrm{l}$ of forward and reverse primers (10 $\mu \mathrm{mol} / \mu \mathrm{l}$; Table I), $0.4 \mu \mathrm{l}$ of Rox Reference Dye II (50X; Takara Biotechnology Co., Ltd.) and $2 \mu \mathrm{l}$ of cDNA. The PCR protocol included 40 cycles with denaturation at $95^{\circ} \mathrm{C}$ for $5 \mathrm{sec}$ and an annealing and extension temperature of $60^{\circ} \mathrm{C}$ for $34 \mathrm{sec}$. The detection of endogenous $\beta$-actin was used as a control. Data were analyzed using the $2^{-\Delta \Delta \mathrm{CT}}$ method, as previously described (29).
Western blot analysis. Following isolation of the proteins from the cells using RIPA buffer containing PMSF (Dingguo Changsheng Biotechnology, Beijing, China), cell lysates were centrifuged $\left(12,000 \mathrm{x} \mathrm{g}, 15 \mathrm{~min}, 4^{\circ} \mathrm{C}\right)$ and the supernatants were collected. The concentrations of total proteins were determined using a BCA kit. Protein samples were boiled for $5 \mathrm{~min}$ in 1X SDS sample buffer [ $50 \mathrm{mM}$ Tris- $\mathrm{HCl}$ (pH 6.8), 20\% glycerol, $2 \%$ SDS, $0.02 \%$ bromophenol blue] containing $2 \% 2$-mercaptoethanol. Extracted proteins were subjected to SDS-PAGE and were then transferred to polyvinylidene difluoride membranes for $3 \mathrm{~h}$ at $4^{\circ} \mathrm{C}$. The membranes were incubated with anti-TLR4, anti-MyD88, and anti-TRAF6 antibodies (1:300), or with antip-IRAK4 and anti-TRIF antibodies $(1: 1,000)$, overnight at $4{ }^{\circ} \mathrm{C}$. After the membranes were washed, they were incubated with the appropriate HRP-conjugated secondary antibodies $(1: 5,000)$ for $45 \mathrm{~min}$ at room temperature. Enhanced chemiluminescence reagents were used to visualize antibody binding which was subsequently quantified using Scion Image 4.0 software (http:// www.bbioo.com/download/58-196-1.html).

ELISA. The concentrations of MMP-13 and IL-6 were detected in the culture supernatants using commercially available ELISA kits (Wuhan Boster Biotechnology,Ltd.), according to the manufacturer's instructions. Data are expressed as the means \pm SD and are representative of 3 independent experiments.

Statistical analysis. All data are expressed as the means \pm SD and were analyzed using one-way analysis of variance (ANOVA) with SPSS 13.0 software (SPSS, Inc., Chicago, IL, USA). A p-value $<0.05$ was considere to indicate a statiscially significant difference.

\section{Results}

Identification of chondrocyte phenotype. Typically, chondrocytes produce large amounts of type II collagen, which compose the extracellular matrix (ECM) along with proteoglycans. Therefore, immunocytochemical methods and toluidine blue staining were used to detect the expression of type II collagen and proteoglycans, respectively, in the third passage chondrocytes that were obtained from the knee articular cartilage of patietns with OA. All the cultured cells exhibited positive staining for type II collagen and 


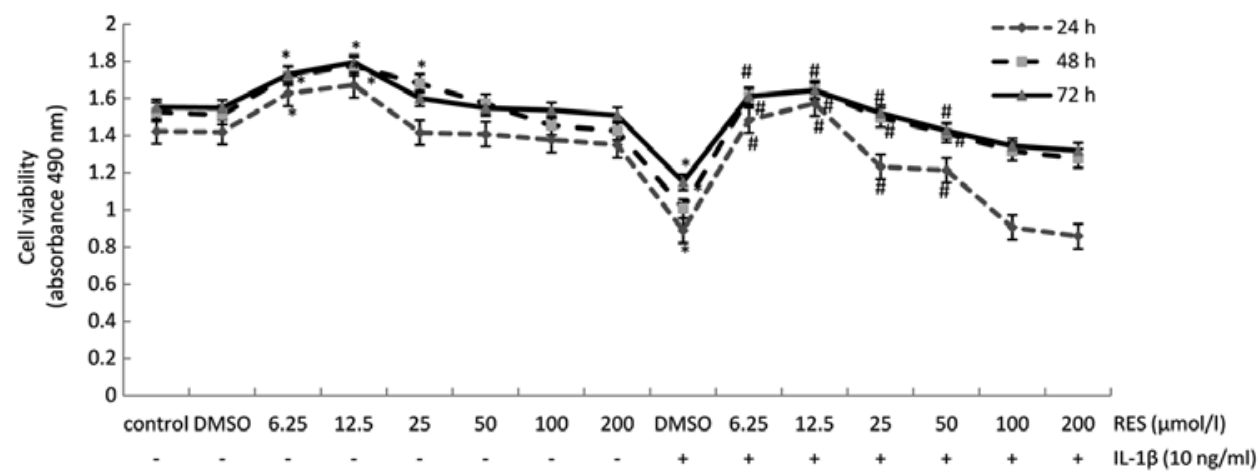

Figure 2. Resveratrol improves the viability of chondrocytes that was inhibited by interleukin (IL)-1 3 . Cultured human articular chondrocytes were treated with various concentrations of resveratrol $(0,6.25,12.5,25,50,100$, and $200 \mu \mathrm{M})$ with or without $10 \mathrm{ng} / \mathrm{ml} \mathrm{IL}-1 \beta$ for 24,48 , or $72 \mathrm{~h}$. Cell viability was subsequently examined by MTS assays. All samples were analyzed in triplicate and the data are expressed as the means \pm SD from 3 independent experiments. ${ }^{*}<0.05$ and ${ }^{\#} \mathrm{p}<0.05$, significant difference vs. control and IL-1 $\beta$, respectively.

A

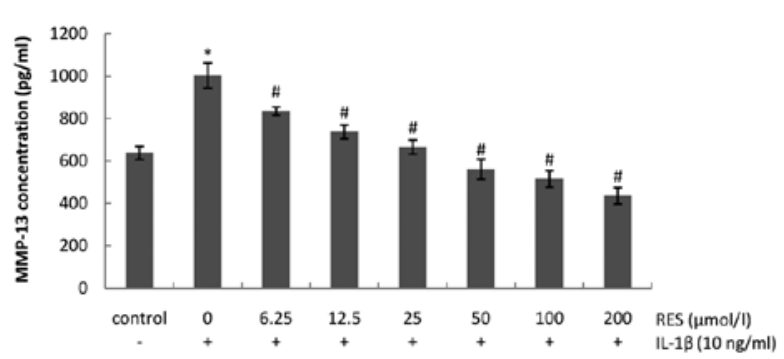

B

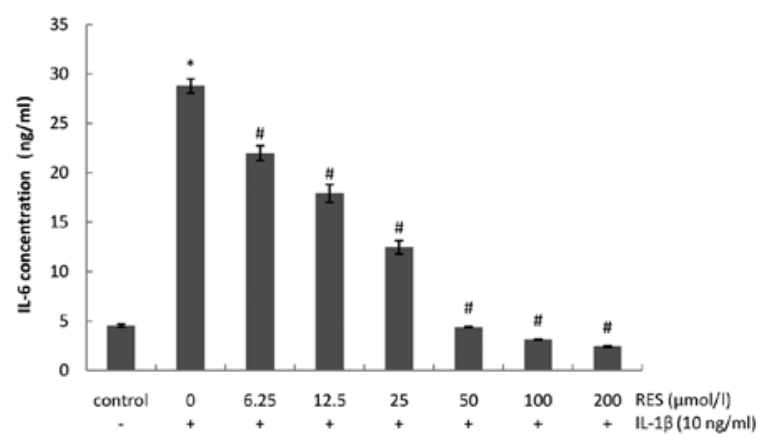

Figure 3. Resveratrol reverses the interleukin(IL)-1 $\beta$-induced upregulation of matrix metalloproteinase (MMP)-13 and IL-6 production. Serum-starved(0.5\% FCS) human articular chondrocytes were incubated with $10 \mathrm{ng} / \mathrm{ml} \mathrm{IL-1} \beta$ for $1 \mathrm{~h}$ and were then co-treated with various concentrations of resveratrol $(0,6.25,12.5,25$, 50,100 , and $200 \mu \mathrm{M}$ ) and $10 \mathrm{ng} / \mathrm{ml}$ IL-1 $\beta$. (A) After $24 \mathrm{~h}$, the concentrations of MMP-13 and (B) IL- 6 in the culture supernatants were determined by ELISA. These assays were performed in triplicate and the data are expressed as the means \pm SD from 3 independent experiments. *p $<0.01$ and ${ }^{\#}<<0.01$, significant difference vs. control and IL-1 $\beta$, respectively.

proteoglycans, thereby demonstrating that chondrocytes were successfully isolated from the knee articular cartilage samples (Fig. 1).

$I L-1 \beta$ decreases cell viability, while resveratrol counteracts these effects of IL-1 $\beta$ in the isolated human articular chondrocytes. As shown by MTS assays that were performed to monitor cell viability, treatment with resveratrol was found to increase chondrocyte cell viability at concentrations of 6.25 and $12.5 \mu \mathrm{M}$ after 24,48 and $72 \mathrm{~h}$. By contrast, exposure to IL-1 $\beta(10 \mathrm{ng} / \mathrm{ml})$ inhibited chondrocyte cell viability. However, resveratrol at concentrations ranging from 6.25 to $50 \mu \mathrm{M}$ resulted in a major increase in cell viability, which was suppressed by exposure to IL-1 $\beta$ (Fig. 2).

Resveratrol inhibits the IL-1 $\beta$-induced production of MMP-13 and $I L-6$. To determine whether resveratrol exerts anti-catabolic and anti-inflammatory effects on IL-1 $\beta$-stimulated chondrocytes, the expression levels of MMP-13 and IL-6 were detected in chondrocyte culture supernatants. As shown in Fig. 3, the levels of MMP-13 and IL-6 were significantly upregulated in the presence of IL-1 $\beta$ (10 ng/ml). By contrast, treatment with resveratrol (6.25-200 $\mu \mathrm{M})$ effectively antagonized these catabolic and inflammatory effects in a dose-dependent manner.
Resveratrol suppresses downstream targets of both TLR4/MyD88-dependent and-independent signaling pathways activated by $I L-1 \beta$ in human articular chondrocytes. To determine whether TLR4/MyD88-dependent and -independent signaling pathways are activated in the presence of IL-1 $\beta$, and to determine whether resveratrol can inhibit their activation, chondrocytes were incubated with IL-1 $\beta(10 \mathrm{ng} / \mathrm{ml})$ for $1 \mathrm{~h}$, were then incubated with or without various concentrations of resveratrol $(6.25-200 \mu \mathrm{M})$ for $24 \mathrm{~h}$. The results of RT-qPCR and western blot analysis were subsequently performed to detect the mRNA and protein levels of various downstream targets of the TLR4 signaling pathway. Exposure to IL-1 $\beta$ induced a marked increase in the mRNA and protein expression levels of the TLR4/MyD88-dependent pathway targets, MyD88, p-IRAK4 and TRAF6, as well as in those of the MyD88-independent pathway target, TRIF. By contrast, resveratrol had an opposite effect, decreasing the levels of these targets (Fig. 4), thereby suggesting that resveratrol exerts an anti-osteoarthritic effect that involves both TLR4/MyD88dependent and -independent signaling pathways.

\section{Discussion}

In normal human joints, articular chondrocytes maintain a dynamic equilibrium between the synthesis and degradation 
A
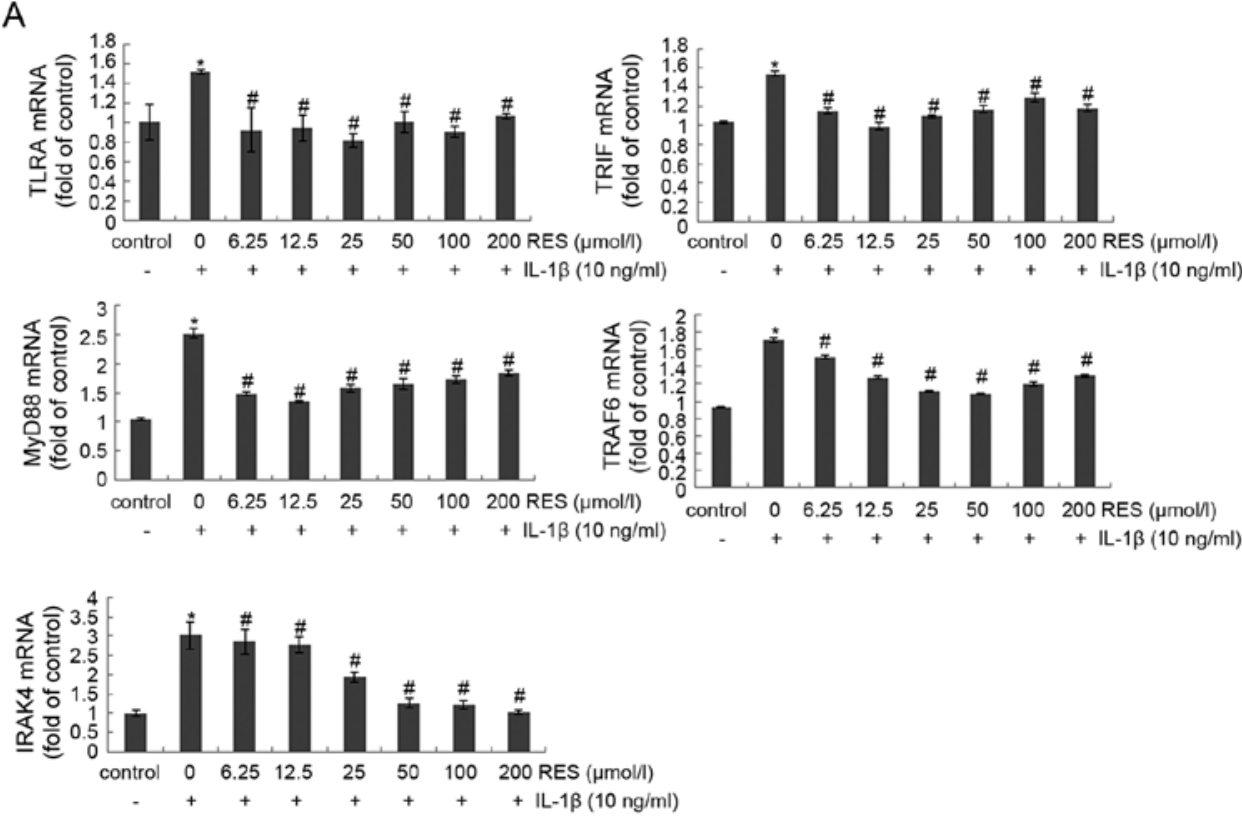

B
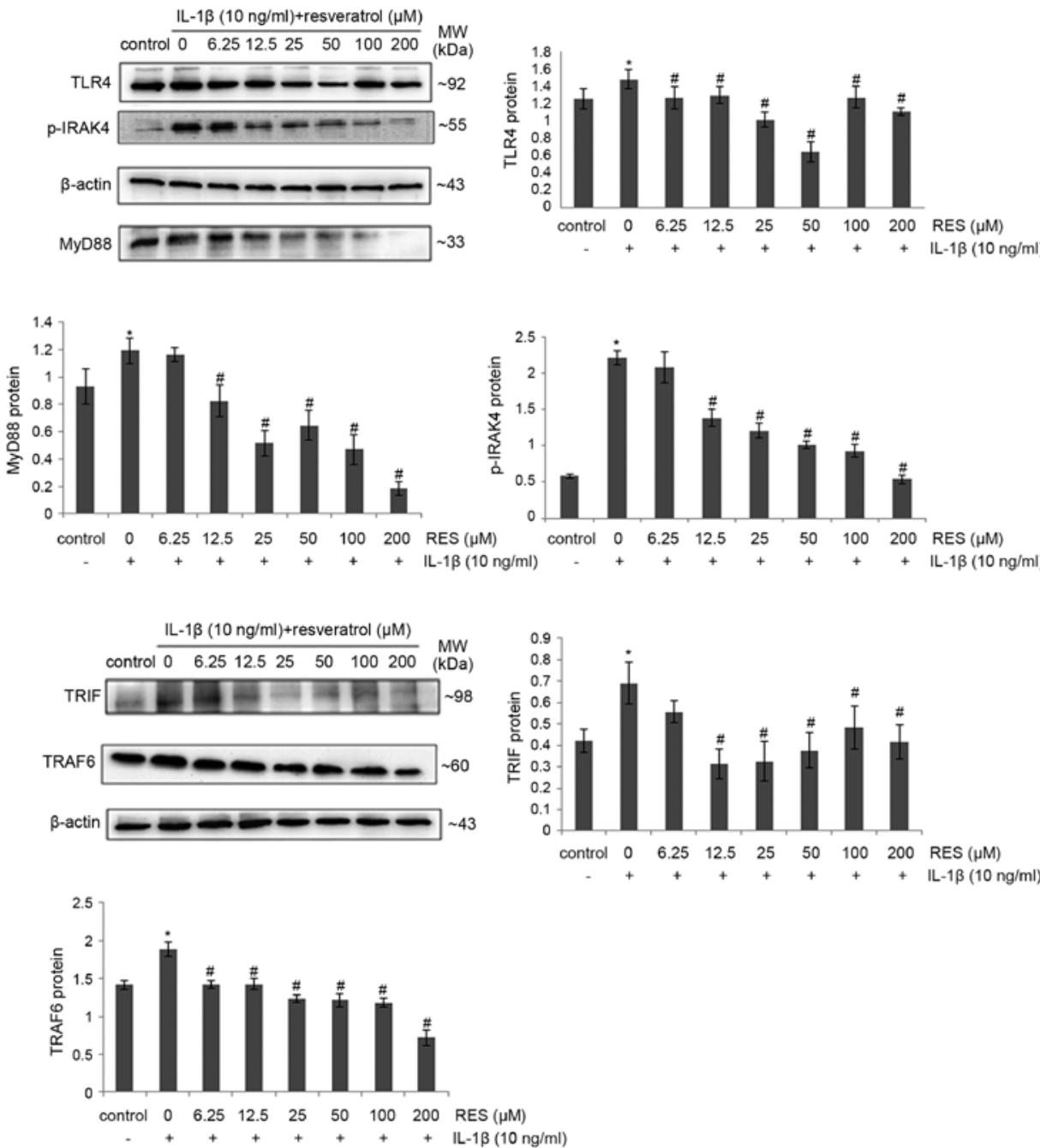

Figure 4. Resveratrol inhibits multiple downstream targets of Toll-like receptor 4 (TLR4)/myeloid differentiation factor 88 (MyD88)-dependent and -independent signaling pathways that were activated by interleukin (IL)-1 $\beta$. Serum-starved ( $0.5 \%$ FCS) human articular chondrocytes were incubated with $10 \mathrm{ng} /$ $\mathrm{ml} \mathrm{IL}-1 \beta$ for $1 \mathrm{~h}$ and were subsequently co-treated with various concentrations of resveratrol $(0,6.25,12.5,25,50,100$, and $200 \mu \mathrm{M}) \mathrm{and} 10 \mathrm{ng} / \mathrm{ml} \mathrm{IL}-1 \beta$. After $24 \mathrm{~h}$, total RNA was collected to perform RT-qPCR and cell lysates were collected for western blot analysis and densitometric analysis. Detection of $\beta$-actin was used as a control. The results represent duplicates of 3 independent experiments that were performed. The levels of (A) mRNA and (B) protein are shown, respectively, for the following targets: TLR4, MyD88, phospho-IL-1 receptor-associated kinase 4 (p-IRAK4), TIR domain-containing adaptor-inducing interferon- $\beta$ (TRIF), and TRAF6. ${ }^{*} \mathrm{p}<0.05$ and ${ }^{\#} \mathrm{p}<0.05$, significant difference vs. control and IL-1 $\beta$, respectively. 
of ECM components (e.g., type II collagen and proteoglycans). However, in OA, perturbations in the normal metabolic properties of chondrocytes result in the destruction of the ECM due to the release of enzymes, such as MMPs (e.g., MMP-1, -3 and -13) and aggrecanases (13). Correspondingly, the overproduction of matrix-degrading enzymes by chondrocytes has been shown to play a central role in matrix degeneration in arthritic cartilage $(30,31)$. Moreover, catabolic mediators, such as IL-1 $\beta$ and IL- 6 have been shown to upregulate these enzymes in cartilage $(32,33)$. In the present study, IL-1 $\beta$ significantly increased the concentrations of MMP-13 and IL-6 that were present in the supernatants assayed, indicating that the equilibrium between the synthesis and degradation of the ECM had been disturbed. Furthermore, the induction of excessive levels of IL- 6 by IL- $1 \beta$ can further degrade cartilage in part by inducing the expression of MMP-13 (34). By contrast, resveratrol was found to reduce the production of MMP-13 and IL-6 in a dosedependent manner, thereby implying that resveratrol can prevent IL-1 $\beta$-induced chondrocyte damage by reducing the production of MMP-13 and IL-6. Resveratrol has previously been shown to antagonize the catabolic factor-mediated upregulation of multiple matrix degrading enzymes, thereby providing evidence that resveratrol has the capacity to slow the catabolic processes that are involved in cartilage degeneration (13). Thus, the findings of the present study suggest that resveratrol counteracts potent inflammatory catabolic factors in chondrocytes, and this confers chondroprotection in OA.

Resveratrol is an anti-inflammatory dietary phytochemical that antagonizes the catabolic effects of TNF- $\alpha$ and IL-1 $\beta$ by inhibiting the $\mathrm{NF}-\kappa \mathrm{B}$ pathway in a variety of tissues $(35,36)$. In our previous study, resveratrol was found to exert a protective effect against the IL-1 $\beta$-induced inflammatory response in human OA-affected chondrocytes, and this was partly mediated by the TLR4/MyD88/NF- $\mathrm{BB}$ signaling pathway (26). The results of a recent study also suggested that MyD88-dependent TLR2/TLR4 signaling may drive the catabolic response of chondrocytes (37). In the present study, both the mRNA and protein levels of TLR4 were increased in chondrocytes stimulated with IL-1 $\beta$, while treatment with resveratrol $(12.5-200 \mu \mathrm{M})$ decreased TLR4 expression. These results are consistent with those of our previous study, and in combination, these results suggest that the TLR4/MyD88 pathway is involved in the pathogenesis of OA. Sebai et al demonstrated that resveratrol may mediate antioxidant properties in either a MyD88-dependent manner that does not involve IRAK1, yet possibly involves IRAK2 or IRAK4, or in a TRIF pathway-dependent manner (27). In the present study, we examined whether IRAK4 contributes to the upregulation of TLR4/MyD88 signaling by IL-1 $\beta$ and the downregulation of this signaling pathway by resveratrol. Our results indicated that IL-1 $\beta$ upregulated $\mathrm{p}$-IRAK4 protein expression, while resveratrol reversed this effect. The present data also confirm the involvement of the MyD88-dependent signaling pathway in the anti-catabolic and anti-inflammatory effects of resveratrol on IL- $1 \beta$-induced OA.

Another interesting finding was that the MyD88-independent pathway (also known as the TRIF signaling pathway) is involved in mediating the protective effects of resveratrol on IL-1 $\beta$-induced human articular chondrocytes. Initially it appeared that MyD88 was required for the signal transduction events engaged by TLR activation. Certain TLR agonists, such as lipopolysaccharide (LPS), have been reported to generate signals dependent on TRIF (38) in the absence of MyD88 (39). The present results demonstrated that TRIF expression was significantly upregulated following exposure to IL-1 $\beta$, whereas the addition of resveratrol reduced TRIF expression. Taken together, these results indicate that MyD88-independent signaling is initiated during OA, and resveratrol exerts protective effects on OA by inhibiting this pathway.

TRAF6 is a component of the MyD88-dependent pathway that activates NF- $\kappa \mathrm{B}$ and controls the expression of genes, such as $T N F \alpha$ and $I L-6(40,41)$. Crosstalk between TRIF and TRAF6 has also been reported in LPS-induced signaling (39). It has been demonstrated that resveratrol suppresses LPS-induced TRAF6 expression and ubiquitination and attenuates LPS-induced TLR4-TRAF6, MAPK and Akt pathways as part of its anti-inflammatory effects (25). In the present study, TRAF6 expression was significantly upregulated following exposure to IL-1 $\beta$, while the addition of resveratrol reduced the expression levels of TRAF6, thereby indicating that both TRAF6-sensitive (and potentially MyD88-dependent) and TRAF6-insensitive (and potentially MyD88-independent and TRIF-dependent) mechanisms are involved in the pathogenesis of OA. Thus, resveratrol appears to exert a protective effect against OA by inhibiting both MyD88-dependent and -independent pathways.

In conclusion, the results of the present study demonstrate that resveratrol exerts protective effects against matrix degradation and inflammation in OA-affected chondrocytes by inhibiting both TLR4/MyD88-dependent and -independent signaling pathways. Thus, resveratrol represents a potential treatment strategy for OA. However, there are several questions that remain to be answered. First, it has to be determined whether the major TLR4 signaling pathway is MyD88-dependent or -independent in resveratrol-treated OA. A genome-wide approach will be critical for defining the individual contributions, and possible redundancies, of these different pathways (39). Second, it also has to be determined whether crosstalk between TLR4 and other signaling pathways, such as the ERK/MAPK pathway and the PI3K/Akt pathway occurs. The results of the present study demonstrated that different concentrations of resveratrol led to the inhibition of TLR4 and its downstream signaling targets to varying degrees, thereby implying that other signaling pathways may also contribute to the effects of resveratrol. Finally, in vivo studies are required in ordre to determine whether the present results are relevant to animal models of OA and have the potential to be translated to patients clinically.

\section{Acknowledgements}

This study was supported by grants from the National Natural Scientific Foundation of China (no. 81372971) and Liaoning Natural Scientific foundation (no. 201202267), P.R. China.

\section{References}

1. Goldring SR: The role of bone in osteoarthritis pathogenesis. Rheum Dis Clin North Am 34: 561-571, 2008.

2. Sofat N, Ejindu V and Kiely P: What makes osteoarthritis painful? The evidence for local and central pain processing. Rheumatology (Oxford) 50: 2157-2165, 2011.

3. Man GS and Mologhianu G: Osteoarthritis pathogenesis - a complex process that involves the entire joint. J Med Life 7: 37-41, 2014. 
4. Scanzello CR, Plaas A and Crow MK: Innate immune system activation in osteoarthritis: is osteoarthritis a chronic wound? Curr Opin Rheumatol 20: 565-572, 2008.

5. Ting JP, Duncan JA and Lei Y: How the noninflammasome NLRs function in the innate immune system. Science 327: 286-290, 2010

6. McCormack WJ, Parker AE and O'Neill LA: Toll-like receptors and NOD-like receptors in rheumatic diseases. Arthritis Res Ther 11: 243, 2009.

7. Haglund L, Bernier SM, Onnerfjord P and Recklies AD: Proteomic analysis of the LPS-induced stress response in rat chondrocytes reveals induction of innate immune response components in articular cartilage. Matrix Biol 27: 107-118, 2008.

8. Schelbergen RF, Blom AB, van den Bosch MH, Slöetjes A, Abdollahi-Roodsaz S, Schreurs BW, Mort JS, Vogl T, Roth J, van den Berg WB and van Lent PL: Alarmins S100A8 and S100A9 elicit a catabolic effect in human osteoarthritic chondrocytes that is dependent on Toll-like receptor 4. Arthritis Rheum 64: 1477-1487, 2012.

9. Abdollahi-Roodsaz S, Joosten LA, Roelofs MF, Radstake TR, Matera G, Popa C, van der Meer JW, Netea MG and van den Berg WB: Inhibition of Toll-like receptor 4 breaks the inflammatory loop in autoimmune destructive arthritis. Arthritis Rheum 56: 2957-2967, 2007.

10. Shotorbani SS, Su ZL and Xu HX: Toll-like receptors are potential therapeutic targets in rheumatoid arthritis. World J Biol Chem 2: 167-172, 2011

11. Bobacz K, Sunk IG, Hofstaetter JG, Amoyo L, Toma CD, Akira S, Weichhart T, Saemann M and Smolen JS: Toll-like receptors and chondrocytes: the lipopolysaccharide-induced decrease in cartilage matrix synthesis is dependent on the presence of toll-like receptor 4 and antagonized by bone morphogenetic protein 7. Arthritis Rheum 56: 1880-1893, 2007.

12. Sgaglione NA: Biologic approaches to articular cartilage surgery: future trends. Orthop Clin North Am 36: 485-495, 2005.

13. Im HJ, Li X, Chen D, Yan D, Kim J, Ellman MB, Stein GS, Cole B, Kc R, Cs-Szabo G and van Wijnen AJ: Biological effects of the plant-derived polyphenol resveratrol in human articular cartilage and chondrosarcoma cells. J Cell Physiol 227: 34883497,2012

14. Yadav M, Jain S, Bhardwaj A, Nagpal R, Puniya M, Tomar R, Singh V, Parkash O, Prasad GB, Marotta F and Yadav $\mathrm{H}$ : Biological and medicinal properties of grapes and their bioactive constituents: an update. J Med Food 12: 473-484, 2009.

15. Eo $\mathrm{SH}$, Cho $\mathrm{H}$ and $\mathrm{Kim} \mathrm{SJ}$ : Resveratrol inhibits nitric oxide-induced apoptosis via the NF-kappa B pathway in rabbit articular chondrocytes. Biomol Ther (Seoul) 21: 364-370, 2013.

16. Csaki C, Keshishzadeh N, Fischer K and Shakibaei M: Regulation of inflammation signalling by resveratrol in human chondrocytes in vitro. Biochem Pharmacol 75: 677-687, 2008

17. Shakibaei M, John T, Seifarth C and Mobasheri A: Resveratrol inhibits IL-1 beta-induced stimulation of caspase- 3 and cleavage of PARP in human articular chondrocytes in vitro. Ann $\mathrm{N} \mathrm{Y}$ Acad Sci 1095: 554-563, 2007.

18. Elmali N, Esenkaya I, Harma A, Ertem K, Turkoz Y and Mizrak B: Effect of resveratrol in experimental osteoarthritis in rabbits. Inflamm Res 54: 158-162, 2005.

19. Elmali N, Baysal O, Harma A, Esenkaya I and Mizrak B: Effects of resveratrol in inflammatory arthritis. Inflammation 30 : $1-6,2007$.

20. Lei M, Wang JG, Xiao DM, Fan M, Wang DP, Xiong JY, Chen Y, Ding Y and Liu SL: Resveratrol inhibits interleukin 1 $\beta$-mediated inducible nitric oxide synthase expression in articular chondrocytes by activating SIRT1 and thereby suppressing nuclear factor- $\kappa$ B activity. Eur J Pharmacol 674: 73-79, 2012

21. Shakibaei M, Mobasheri A and Buhrmann C: Curcumin synergizes with resveratrol to stimulate the MAPK signaling pathway in human articular chondrocytes in vitro. Genes Nutr 6 : 171-179, 2011.

22. Eo SH, Cho HS and Kim SJ: Resveratrol regulates type II collagen and COX-2 expression via the ERK, p38 and Akt signaling pathways in rabbit articular chondrocytes. Exp Ther Med 7: 640-648, 2014.

23. Han KJ, Su X, Xu LG, Bin LH,Zhang J and Shu HB: Mechanisms of the TRIF-induced interferon-stimulated response element and NF-kappaB activation and apoptosis pathways. J Biol Chem 279: 15652-15661, 2004.

24. Baumgarten G, Knuefermann P, Nozaki N, Sivasubramanian N, Mann DL and Vallejo JG: In vivo expression of proinflammatory mediators in the adult heart after endotoxin administration: the role of toll-like receptor-4. J Infect Dis 183: 1617-1624, 2001.
25. Jakus PB, Kalman N, Antus C, Radnai B, Tucsek Z, Gallyas F Jr, Sumegi B and Veres B: TRAF6 is functional in inhibition of TLR4-mediated NF- $\kappa$ B activation by resveratrol. J Nutr Biochem 24: 819-823, 2013

26. Liu L, Gu H, Liu H, Jiao Y, Li K, Zhao Y, An L and Yang J: Protective effect of resveratrol against IL-1 $\beta$-induced inflammatory response on human osteoarthritic chondrocytes partly via the TLR4/MyD88/NF- $\mathrm{BB}$ signaling pathway: an 'in vitro study'. Int J Mol Sci 15: 6925-6940, 2014.

27. Sebai H, Ristorcelli E, Sbarra V, Hovsepian S, Fayet G, Aouani E and Lombardo D: Protective effect of resveratrol against LPS-induced extracellular lipoperoxidation in AR42J cells partly via a Myd88-dependent signaling pathway. Arch Biochem Biophys 495: 56-61, 2010

28. Jung DY, Lee H, Jung BY, Ock J, Lee MS, Lee WH and Suk K: TLR4, but not TLR2, signals autoregulatory apoptosis of cultured microglia: a critical role of IFN-beta as a decision maker. J Immunol 174: 6467-6476, 2005.

29. Livak KJ and Schmittgen TD: Analysis of relative gene expression data using real-time quantitative PCR and the 2(-Delta Delta C(T)) method. Methods 25: 402-408, 2001.

30. Vincenti MP and Brinckerhoff CE: Transcriptional regulation of collagenase (MMP-1, MMP-13) genes in arthritis: integration of complex signaling pathways for the recruitment of gene-specific transcription factors. Arthritis Res 4: 157-164, 2002

31. Yammani RR, Carlson CS, Bresnick AR and Loeser RF: Increase in production of matrix metalloproteinase 13 by human articular chondrocytes due to stimulation with S100A4: role of the receptor for advanced glycation end products. Arthritis Rheum 54: 2901-2911, 2006.

32. Im HJ, Pacione C, Chubinskaya S, Van Wijnen AJ, Sun Y and Loeser RF: Inhibitory effects of insulin-like growth factor-1 and osteogenic protein-1 on fibronectin fragment- and interleukin-1beta-stimulated matrix metalloproteinase-13 expression in human chondrocytes. J Biol Chem 278: 25386-25394, 2003.

33. Muddasani P, Norman JC, Ellman M, van Wijnen AJ and Im HJ: Basic fibroblast grow th factor activates the MAPK and NFkappaB pathways that converge on Elk-1 to control production of matrix metalloproteinase- 13 by human adult articular chondrocytes. J Biol Chem 282: 31409-31421, 2007.

34. Legendre F, Bogdanowicz P, Boumediene K and Pujol JP: Role of interleukin 6 (IL-6)/IL-6R-induced signal tranducers and activators of transcription and mitogen-activated protein kinase/extracellular. J Rheumatol 32: 1307-1316, 2005.

35. Estrov Z, Shishodia S, Faderl S, Harris D, Van Q, Kantarjian HM, Talpaz M and Aggarwal BB: Resveratrol blocks interleukin-1betainduced activation of the nuclear transcription factor NF-kappaB, inhibits proliferation, causes S-phase arrest, and induces apoptosis of acute myeloid leukemia cells. Blood 102: 987-995, 2003.

36. Kundu JK, Shin YK and Surh YJ: Resveratrol modulates phorbol ester-induced pro-inflammatory signal transduction pathways in mouse skin in vivo: NF-kappaB and AP-1 as prime targets. Biochem Pharmacol 72: 1506-1515, 2006.

37. Liu-Bryan R and Terkeltaub R: Chondrocyte innate immune myeloid differentiation factor 88-dependent signaling drives procatabolic effects of the endogenous Toll-like receptor $2 /$ Toll-like receptor 4 ligands low molecular weight hyaluronan and high mobility group box chromosomal protein 1 in mice. Arthritis Rheum 62: 2004-2012, 2010.

38. Weighardt H, Jusek G, Mages J, Lang R, Hoebe K, Beutler B and Holzmann B: Identification of a TLR4- and TRIF-dependent activation program of dendritic cells. Eur J Immunol 34: 558-564, 2004.

39. Björkbacka H, Fitzgerald KA, Huet F, Li X, Gregory JA, Lee MA, Ordija CM, Dowley NE, Golenbock DT and Freeman MW: The induction of macrophage gene expression by LPS predominantly utilizes Myd88-independent signaling cascades. Physiol Genomics 19: 319-330, 2004.

40. Jiang Z, Mak TW, Sen G and Li X: Toll-like receptor 3-mediated activation of NF-kappaB and IRF3 diverges at Toll-IL-1 receptor domain-containing adapter inducing IFN-beta. Proc Natl Acad Sci USA 101: 3533-3538, 2004.

41. Sato S, Sugiyama M, Yamamoto M, Watanabe Y, Kawai T, Takeda K and Akira S: Toll/IL-1 receptor domain-containing adaptor inducing IFN-beta (TRIF) associates with TNF receptor-associated factor 6 and TANK-binding kinase 1 , and activates two distinct transcription factors, NF-kappa B and IFN-regulatory factor-3, in the Toll-like receptor signaling. J Immunol 171: 4304-4310, 2003. 